\title{
DIODE LASER- AN EVOLUTIONARY TOOL FOR MANAGEMENT OF ORAL MUCOSAL LESIONS
}

\author{
Priyadershini Rangari', Malwinder Cheema²
}

${ }^{1}$ Assistant Professor, Department of Dentistry, Sri Shankaracharya Institute of Medical Sciences, Bhilai, Durg, Chhattisgarh. 2MDS, (Oral Medicine and Radiology), Mohali, Punjab.

ABSTRACT

\section{BACKGROUND}

LASER is an acronym for Light Amplification by Stimulated Emission of Radiation. Lasers are heat producing devices converting electromagnetic energy into thermal energy. The characteristic of a laser depends on its wavelength (WL) and wavelength affects both the clinical applications and design of laser.

\section{MATERIALS AND METHODS}

This prospective observational study was done on the patients to evaluate the utility of laser in the treatment of various mucosal lesions. A total of 30 patients of either sexes and in age ranging from 20 - 70 years with various mucosal lesions like surface lesions, exophytic lesions, ulcerative lesions and mucocele were selected. They were divided into four groups, which were prepared and treated by Laser therapy using Diode Laser - DC Lase 980nm, 7W. All the subjects in each group were evaluated before, during and after laser therapy for various parameters like pain, bleeding, charring, healing, mouth opening, anxiety, difficulty in eating/drinking and taste alteration. They were followed up at regular interval of 1 week, 2 weeks and 1 month.

\section{RESULTS}

The results thus obtained were compiled and analysed which accelerated wound healing, decreased postoperative discomfort, less thermal necrosis and adequate haemostasis without need for sutures. The procedure was easy, comfortable to patient and operator with reduced operator chair time.

\section{CONCLUSION}

Thus, Lasers offer many useful clinical applications in the field of oral medicine for the management of patients with different types of oral mucosal lesions.

\section{KEYWORDS}

Diode Laser, Oral Mucosal Lesions, Potentially Malignant, Bloodless Surgery.

HOW TO CITE THIS ARTICLE: Rangari P, Cheema M. Diode laser- an evolutionary tool for management of oral mucosal lesions. J. Evolution Med. Dent. Sci. 2018;7(17):2129-2133, DOI: 10.14260/jemds/2018/476

\section{BACKGROUND}

LASER is an acronym for Light Amplification by Stimulated Emission of Radiation. Lasers are heat producing devices converting electromagnetic energy into thermal energy. The characteristic of a laser depends on its wavelength (WL) and wavelength affects both the clinical applications and design of laser. The WL used in dentistry generally range from 193 to $10600 \mathrm{~nm}$, representing a broad spectrum from ultraviolet to the far infrared range.

Since the development of the ruby laser by Maiman in 1960, there has been great interest among dental practitioners to use this tool to make dental treatment more pleasant. In the literature, laser has been recommended for the treatment of benign oral lesions like fibroma, haemangioma, papilloma, idiopathic gingival hyperplasia or gingival hyperplasia, aphthous ulcer, mucosal frenula or tongue-tie (Ankyloglossia) as well as potentially malignant oral lesions such as oral leukoplakia, erythroplakia, lichen planus etc. Some reports on the use of the laser also support the possibility of treating malignant oral diseases in early

'Financial or Other Competing Interest': None.

Submission 12-03-2018, Peer Review 06-04-2018,

Acceptance 12-04-2018, Published 23-04-2018.

Corresponding Author:

Dr. Priyadershini Rangari,

B7/1, Chouhan Green Valley,

Junwani, Bhilai-District, Durg-490020,

Chhattisgarh.

E-mail: drpriyakasture@gmail.com

DOI: $10.14260 /$ jemds $/ 2018 / 476$ stages (for example, T1N0 carcinomas) with excisional biopsies. Lasers are also used in dentistry for endodontic and periodontal surgeries. ${ }^{1}$

Diode lasers have a wavelength of 620 to $900 \mathrm{~nm}$ and are used to treat oral soft tissue lesions. One of the applications of lasers in dentistry is soft tissue surgery and ablation of lesions. The excision of exophytic lesions is one of the uses. Laser transmits energy to the cells causing warming, welding, coagulation, protein denaturation, drying, vaporisation and carbonisation. The diode laser was introduced in dentistry and oral surgery in the mid-90s.

Diode laser devices have many advantages such as relatively small size, portable and lower cost that attract the dental practitioners and oral surgeons for use in various surgical indications in comparison to other laser equipment. The pump source is an electrical current, the photons are produced by electric current and laser active medium is semiconductor.

The advantages of laser application are relatively bloodless surgery, minimal swelling, scarring and coagulation. No need for suturing, reduction in surgical time and less or no postsurgical pain. Also, the laser instantly disinfects the surgical wound as well as allowing a noncontact type of operative procedure and therefore no mechanical trauma to the tissue.

There are some disadvantages too, operations of lasers are highly expensive and require specialised training. Dental instruments mainly used are both sides and end cutting; thus, a modification of clinical technique is required. No single 
wavelength will optimally treat all dental disease. Moreover, they are harmful to eyes and skin.1,2

Over the past few decades, the use of lasers among oral and maxillofacial lesions has grown dramatically. Therefore, this study was undertaken with the sole aim of determining the utility of diode laser in the treatment of various oral mucosal lesions.

\section{MATERIALS AND METHODS}

The prospective observational study was comprised of 30 subjects in the age group of 20 - 70 years, who were diagnosed for various oral mucosal lesions. The selection of patients was done from those attending the Outpatient Department of Oral Medicine Radiology irrespective of age, sex, race, religion and socio-economic status.

The inclusive criteria were subjects diagnosed for various oral mucosal lesions like oral lichen planus, leukoplakia, recurrent aphthous ulcers, irritational fibroma, mucocele etc. Subjects were selected considering the extent and nature of the oral mucosal lesion and ease of accessibility to treat with laser.

The exclusion criteria was subjects with extensively large oral mucosal lesions and having potential risk of malignancy and with systemic problems like uncontrolled hypertension, uncontrolled diabetes and under immunosuppressive therapy.

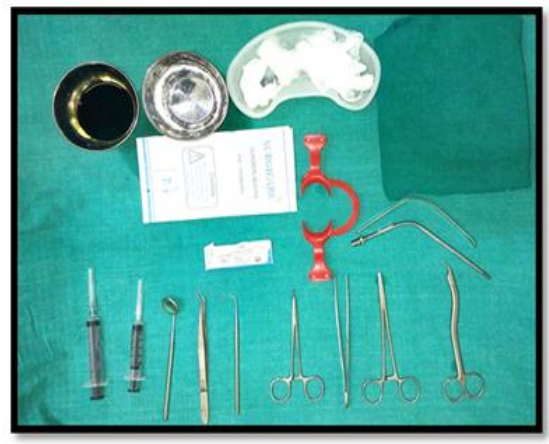

Figure 1. Showing Armamentarium for Surgical Procedure

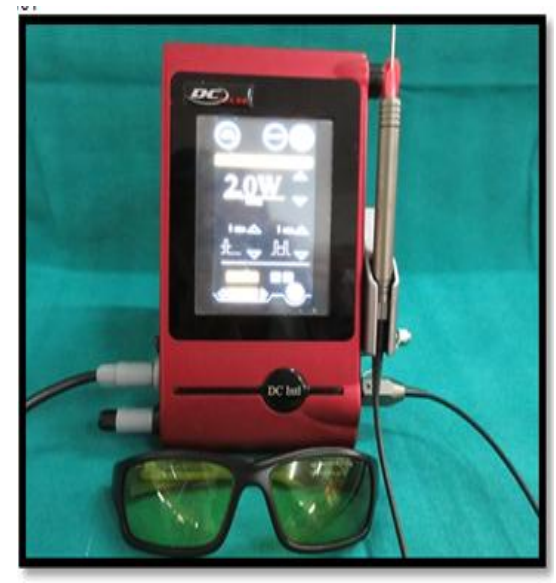

Figure 2. Diode Laser

For this study, 30 subjects with various oral mucosal lesions were selected. For each selected subject, detailed case history and thorough clinical examination was noted down on the proforma. A provisional clinical diagnosis was made after doing radiological and haematological investigations. All the patients were informed in detail about the study in their language and a written consent was obtained.

These Subjects were Randomly Divided into 4 Groups-

Group I: Consisted of 7 patients having oral mucosal surface lesions.

Group II: Consisted of 18 patients having oral mucosal exophytic lesions.

Group III: Consisted of 2 patients having Mucocele.

Group IV: Consisted of 3 patients having recurrent aphthous stomatitis.

\section{Methodology \\ For the Subjects in Group I}

The patients having oral mucosal surface lesions namely Leukoplakia and Oral Lichen Planus were diagnosed clinically and selected for the study. The complete procedure was explained to patients. Local anaesthesia was achieved using $2 \mathrm{~mL}$ of xylocaine with adrenaline 1:80,000. With the help of diode laser unit (DC Lase $980 \mathrm{~nm}, 7 \mathrm{~W}$ ) at power of 2 Watts and $400 \mu \mathrm{m}$ flexible fibreoptic delivery system in contact mode, an elliptical margin of $0.5 \mathrm{~cm}$ away from the border of lesion was created keeping the laser tip perpendicular to the mucosal surface. The margins were pulled away with the help of a toothed forceps and the lesion was excised at the base all over keeping the tip in an oblique direction. The specimen of the lesion thus obtained was collected and sent for histopathological examination. The remnants of the lesion were ablated and removed using sterile gauze dipped in saline.

\section{For the Subjects in Group II}

The patients having oral mucosal exophytic lesions like pyogenic granuloma, irritational fibroma, fibropyogenic granuloma, papillary hyperplasia and fibrous hyperplasia. Sling suture was passed through the lesion for holding and retracting the lesion, making the base accessible. The lesion was excised completely from its base. Rest of the procedure was same as Group I.

\section{For the Subjects in Group III}

Having mucocele. Removal of the lesions was performed by unroofing it first and completely excising it along with gland tissue later on. Rest of the procedure was same as Group I.

\section{Subjects in Group IV}

They were having recurrent aphthous ulcers and they were treated by Low Level Laser Therapy (LLLT). The application of laser was done in non-contact mode with the distance of 2 $3 \mathrm{~mm}$ between the laser tip and the surface of ulcer. The laser beam was applied in a continuous circular motion, covering the entire ulcer surface. The cooling interval of 20 secs was given in between the passes. All the subjects in each group were evaluated before, during and after laser therapy for various parameters like pain, anxiety, bleeding, charring, healing, mouth opening, difficulty in eating/ drinking and taste alteration. Post-operative instructions and medications were given wherever necessary. They were followed up at 1 week, 2 weeks and 1 month interval (except for Group IV patients who were followed for 1 week only). 


\section{RESULTS}

This study consisted of total 30 subjects with various mucosal lesions like surface lesions, exophytic lesions, mucocele and RAS. They include 18 males (60\%) and 12 females (40\%). Age range for total subjects was from 20 to 70 years with the mean age of 42.03 (S.D. +13.97 ) years. Among the males, age range was from 20 to 70 years with the mean age of 42.5 (S.D. +15.65 ) years and for females age range was from 22 to 60 years with the mean age of 41.25 (S.D. + 11.6) years as shown in Table 1.

\begin{tabular}{|l|c|c|c|c|c|c|}
\hline \multirow{2}{*}{$\begin{array}{c}\text { Sr. } \\
\text { No. }\end{array}$} & \multirow{2}{*}{ Sex } & \multirow{2}{*}{ Number } & \multirow{2}{*}{$\%$} & \multicolumn{3}{|c|}{ Age (In Years) } \\
\cline { 5 - 7 } & & & & Min & Max & Mean (+SD) \\
\hline 1 & Male & 18 & $60 \%$ & 20 & 70 & $42.5(15.65)$ \\
\hline 2 & Female & 12 & $40 \%$ & 22 & 60 & $41.25(11.6)$ \\
\hline \multicolumn{2}{|c|}{ Total } & $\mathbf{3 0}$ & $\mathbf{1 0 0}$ & $\mathbf{2 0}$ & $\mathbf{7 0}$ & $\mathbf{4 2 . 0 3}(13.97)$ \\
\hline \multicolumn{6}{|c|}{ Table 1. Distribution of Subjects according to Age and Sex } \\
\hline
\end{tabular}

Distribution of various lesions and their frequency and percentage shown in Table 2.

\begin{tabular}{|c|c|c|c|}
\hline Sl. No. & Various Groups & No. of Patients & $(\%)$ \\
\hline 1 & Group I (Surface Lesions) & 7 & 23 \\
\hline 2 & $\begin{array}{c}\text { Group II } \\
\text { (Exophytic Lesions) }\end{array}$ & 18 & 60 \\
\hline 3 & Group III (Mucocele) & 2 & 7 \\
\hline 4 & $\begin{array}{c}\text { Group IV } \\
\text { (Ulcerative Lesions) }\end{array}$ & 3 & 10 \\
\hline & Total & 30 & 100 \\
\hline \multicolumn{4}{|c|}{ Table 2. Distribution of Various Lesions } \\
\hline
\end{tabular}

Age range for patients in Group I was 35 - 70 years with a mean age of 56.14 (S.D. + 11.05) years; in Group II it was 20 60 years with a mean age of 38.2 (S.D. + 12.37) years and in Group III patients with mucocele whose age was 21 - 34 years with the mean age of 27.5 (S.D. + 9.19) and in Group IV it was 32 - 51 years with the mean age of 41.5 (S.D. + 9.53).

\begin{tabular}{|c|c|c|c|c|c|c|}
\hline Sl. & \multirow{2}{*}{ No. } & Troup & Total & \multicolumn{4}{|c|}{ Age in Years } \\
\cline { 2 - 7 } & & Min & Max & Mean & S.D. \\
\hline 1 & Group I & 7 & 35 & 70 & 56.1 & 11.05 \\
\hline 2 & Group II & 18 & 20 & 60 & 38.2 & 12.37 \\
\hline 3 & Group III & 2 & 21 & 34 & 27.5 & 9.19 \\
\hline 4 & Group IV & 3 & 32 & 51 & 41 & 9.53 \\
\hline \multicolumn{3}{|c|}{ Table 3. Age Distribution in Different Groups } \\
\hline
\end{tabular}

In this study out of 30 subjects, 18 were males and 12 were females. Group I with surface lesions included 5 males (17\%) and 2 females (7\%); Group II with Exophytic lesions had 11 males (37\%) and 7 females (23\%) and Group III with mucocele included 1 male (3\%) and 1 female (3\%) and Group IV with RAS included 1 male (3\%) and 2 females (7\%). Percentage within group was also calculated.

\begin{tabular}{|c|c|c|c|c|c|}
\hline Sl. & \multicolumn{2}{|c|}{ Group } & \multicolumn{2}{c|}{ Gender } & \multirow{2}{*}{ Total } \\
\cline { 2 - 5 } No. & \multicolumn{2}{|c|}{ Males } & Females & \\
\hline \multirow{2}{*}{1} & Group I & Count & 5 & 2 & 7 \\
\cline { 2 - 5 } & & $\begin{array}{c}\text { \% Within in } \\
\text { group }\end{array}$ & $71 \%$ & $29 \%$ & \\
\hline
\end{tabular}

\begin{tabular}{|c|c|c|c|c|c|}
\hline & & $\begin{array}{l}\text { \% Within in } \\
\text { gender }\end{array}$ & $28 \%$ & $17 \%$ & \\
\hline \multirow{3}{*}{2} & Group II & Count & 11 & 7 & 18 \\
\hline & & $\begin{array}{l}\text { \% Within in } \\
\text { group }\end{array}$ & $61 \%$ & $39 \%$ & \\
\hline & & $\begin{array}{l}\text { \% Within in } \\
\text { gender }\end{array}$ & $61 \%$ & $58 \%$ & \\
\hline \multirow{3}{*}{3} & $\begin{array}{l}\text { Group } \\
\text { III }\end{array}$ & Count & 1 & 1 & 2 \\
\hline & & $\begin{array}{l}\text { \% Within in } \\
\text { group }\end{array}$ & $50 \%$ & $50 \%$ & \\
\hline & & $\begin{array}{c}\% \text { Within in } \\
\text { gender }\end{array}$ & $5.5 \%$ & $8 \%$ & \\
\hline \multirow{3}{*}{4} & $\begin{array}{l}\text { Group } \\
\text { IV }\end{array}$ & Count & 1 & 2 & 3 \\
\hline & & $\%$ Within group & $33 \%$ & $67 \%$ & \\
\hline & & $\begin{array}{c}\text { \% Within } \\
\text { gender }\end{array}$ & $5.5 \%$ & $17 \%$ & \\
\hline & \multicolumn{5}{|c|}{ Table 4. Gender Wise Distribution of Each Group } \\
\hline
\end{tabular}

\section{DISCUSSION}

During the evaluation, no significant post-operative pain was presented by the patients immediately and during the followup period of 1 month, except for one patient who experienced significant pain during the follow-up period and was pain free on last visit at 1 month. This was probably due to deeper excision and subsequent secondary infection, which delayed healing and development of pain. These results were consistent with the findings of Agha-Hosseini F (2012) ${ }^{3}$ and Hazeem I Muhamed et al (2013), ${ }^{4}$ Sarkar et al (2015) ${ }^{5}$ made similar observation in their study and found that in-operative and post-operative reduction in pain by laser surgical procedure.

Intraoperative and postoperative bleeding was assessed in all patients. Laser procedure was not associated with intraoperative and postoperative bleeding. These findings are in similarity to Butchi et al (2015), ${ }^{6}$ who observed lack of bleeding by diode laser. Agha-Hosseini F (2012) ${ }^{3}$ and Sarkar et al $(2015)^{5}$ also observed excellent haemostasis in their study on laser treatment in oral leukoplakia.

In Group I, patients had charring involving both the sites, base as well as periphery during and immediately after the procedure because of high temperature and caused carbonisation of marginal tissues as explained by Butchi et al (2015). ${ }^{6}$ Laser transmits energy to the cells causing warming, welding, coagulation, protein denaturation, drying, vaporisation and carbonisation.

The findings of our study are in accordance with studies by Azma E et al (2013) ${ }^{7}$ and Kumar P et al (2015). ${ }^{8}$

In this Group, satisfactory healing was observed in all except one patient during the first follow-up visit. One patient with homogenous leukoplakia lesion showed non-satisfactory healing during the first visit, but complete epithelialisation was observed in 1 month.

Kumar P et al $(2015)^{8}$ and Sarkar et al $(2015)^{5}$ also observed similar results of complete epithelialisation within 3 weeks.

Most of the patients did not have any postoperative restricted mouth opening, which was consistent with the study by Kumar P et al (2015).8 Only one patient presented with complaint of restriction in mouth opening after the procedure, which persisted throughout the follow-up period also till 1 month. 
Patients in Group I was anxious about the nature of the lesion and the surgical procedure to be undertaken for treatment purpose. During the procedure while performing the incision/ excision some fumes were released from epithelium with the burning smell, which provoked stress in the patients as reported by Azma et al (2013).7 This anxiety and stress was released subsequently by uneventful healing in most of the patients.

No significant loss of function in terms of eating or drinking and taste was observed. Similar results were postulated by Sarkar et al (2015). 5

In Group II during the evaluation of pain, only few patients showed the score between $0-3$ which indicated minimal pain. This also reduced during the follow-up period of 2 weeks to 1 month. These results are in accordance with Gupta et al (1999) ${ }^{9}$ and Rai S et al (2011) ${ }^{2}$ who reported minimal postoperative pain as lasers transiently depolarises nerves.

For evaluation of bleeding in this group, it was observed that 10 cases were associated with oozing during the surgical procedure and only one patient showed active bleeding which was easily arrested by charring of bleeding points. The results of our study were in accordance with those by Azma et al (2013) ${ }^{7}$ and Rai J et al (2011), ${ }^{2}$ who observed that haemostasis occurred on surface of wound after laser radiations.

Charring was observed either at base or at the periphery of the wound created after excision, which vanished during follow-up. Charring occur with laser if sufficient power density and exposure duration are provided as proposed by Husin M et al (2005) ${ }^{10}$ and Azma et al (2013). ${ }^{7}$

Rapid healing was observed within few days. This finding was consistent with those reported by Rai et al (2011), ${ }^{2}$ Akbulut et al (2013) ${ }^{11}$ and Azma E et al (2013). ${ }^{7}$

No patient reported any restriction in mouth opening during the follow-up period. Butchi et al $(2015)^{6}$ and Goldstep (2009) ${ }^{12}$ reported that laser excision is well tolerated by patients with no adverse effects.

No significant difficulty in eating reported by any of the patients except for patients having lesion on the lateral border of tongue. May be this difficulty was due to the postoperative wounds created on the tongue and active participation of tongue is required for mastication and swallowing. Goldstep (2009) ${ }^{12}$ and Rai et al (2011) ${ }^{2}$ also reported good patient acceptance after laser surgery.

None of the patients reported any symptoms of taste alteration during the study. These results are in agreement with those reported by Azma et al (2013). ${ }^{7}$

In Group III none of the patients reported significant pain, bleeding and charring after laser excision of the mucocele. Similar findings were reported by Goldstep (2009), ${ }^{12}$ Husin M C et al (2005) ${ }^{10}$ and Azma E et al (2013). ${ }^{7}$

Excellent healing was observed. Similar results were reported by Babu Butchi et al $(2015)^{6}$ and Sarkar et al (2015)..$^{5}$

Patients were anxious during surgery, but subsequent visits showed minimal anxiety. Similar observations were made by Azma et al (2013). ${ }^{7}$

Mild-to-moderate difficulty in eating was reported during the first week post-operatively, which disappeared completely during the following visits. The results of study were in accordance with Sarkar et al (2015) ${ }^{10}$ and Rai et al (2011), ${ }^{2}$ who reported good patient acceptance after laser surgery.

In Group IV total 3 patients having RAS were treated by laser therapy in non-contact mode.

In all 3 patients, significant pain was present preoperatively as evident from pain score VAS scale 5 and/or 6 . No pain was felt by any patient during the procedure. Considerable reduction in pain was reported immediately after the procedure by all 3 patients who disappeared completely at 1 week. The results of our study were similar to Gupta et al (1999), ${ }^{9}$ De Souza et al (2010) ${ }^{13}$ and Abraham et al. ${ }^{1}$ The thermal necrosis created by tissue vaporisation cause sealing of the ends of the sensory nerves, decrease their ability to transmit stimuli reported by Gupta et al (1999) ${ }^{9}$ and Sarkar et al (2015). ${ }^{5}$

All the patients showed satisfactory-to-good healing during follow-up period. These findings are consistent with earlier studies done by Rai et al $(2011)^{2}$ and Azma et al (2013). ${ }^{7}$

There was significant difficulty reported in eating or drinking by patients preoperatively, which minimised after laser therapy and was indicated by the response obtained at first week. The results of study were in accordance with Albrektson $\mathrm{M}$ et al (2014). ${ }^{14}$

Patients were anxious before and during the procedure shown by ALI score, but anxiety score became 0 after the procedure and patients were comfortable. These results are inconsistent with those reported by Azma et al (2013). ${ }^{7}$

\section{Limitation}

Due to low sample size taken out of convenience, result cannot be generalised.

\section{CONCLUSION}

Laser technology has made rapid progress over the past few decades. Because of its many advantages, it has been widely used in the field of oral medicine. Soft tissue laser is a stateof-the-art tool that allows treating various oral mucosal pathologies. This clinical trial was done on the patients to evaluate the utility of laser in the treatment of various mucosal lesions. The postoperative results obtained were adequate haemostasis without need for sutures, reduced operator chair time, decontaminating and bactericidal properties, accelerated wound healing, less discomfort, less thermal necrosis of adjacent tissues, thus reduced need for antibiotics. Immediate pain relief and inflammation was observed with aphthous ulcers. Large sample size was needed for the generalised results.

Hence, Lasers may offer many useful clinical applications in the field of oral medicine for the management of different types of oral mucosal lesions.

\section{REFERENCES}

[1] Abraham RJ, Lankupalli AS. Laser management of intraoral soft tissue lesions - a review of literature. IOSR-JDMS 2014;13(1):59-64.

[2] Rai S, Kaur M, Bhatnagar P. Laser: a powerful tool for treatment of pyogenic granuloma. J Cutan Aesthet Surg 2011;4(2):144-7. 
[3] Agha-Hosseini F, Moslemi E, Mirzaii-Dizgah I, Comparative evaluation of low level laser and $\mathrm{CO}_{2}$ laser in treatment of patients with oral lichen planus. Int J Oral Maxillofacial Surg 2012;41(10):1265-9.

[4] Hazeem MI, Rajab MS, Badeia RA. Treatment of recurrent aphthous stomatitis with $940 \mathrm{~nm}$ diode laser. Tikrit Journal for Dental Sciences 2013;1:77-82.

[5] Sarkar S, Kailasam S, Iyer VH. Effectiveness of diode laser and Er, Cr: YSGG laser in the treatment of oral leukoplakia - a comparative study. Dentistry 2015;5:274.

[6] Butchi B. The effects of low power lasers in healing of oral ulcers. Journal of Lasers in Medical Sciences 2015;3(2):43-7.

[7] Azma E, Safavi N. Diode laser application in soft tissue oral surgery. J Lasers Med Sci 2013;4(4):206-11.

[8] Kumar P, Rattan V, Rai S. Comparative evaluation of healing after gingivectomy with electrocautery and laser. J Oral Biol Craniofac Res 2015;5(2):69-74.
[9] Gupta S, Kumar S. Lasers in dentistry - an overview. Trends Biomater. Artif. Organ 2011;25(3):119-23.

[10] Husein A. Applications of lasers in dentistry: a review. Archives of Orofacial Sciences 2006;1(1):1-4.

[11] Akbulut N, Kursun ES, Tumer MK, et al. Is the 810-nm diode laser the best choice in oral soft tissue therapy? Eur J Dent 2013;7(2):207-11.

[12] Goldstep F. Soft tissue diode laser: Where have you been all my life? Oral Health 2009: p. 34-8.

[13] De Souza TO, Martins MA, Bussadori SK, et al. Clinical evaluation of low-level laser treatment for recurring aphthous stomatitis. Photomed laser Surg 2010;28(Suppl 2):S85-S8.

[14] Albrektson M, Hedstrom L, Bergh H. Recurrent aphthous stomatitis and pain management with lowlevel laser therapy: a randomized controlled trial. Oral Surg Oral Med Oral Pathol Oral Radiol 2014;117(5):590-4. 